\title{
Simple Method to Synthesize Functionalized Carbon Nanotubes Employing Cobalt Nitrate and Acetone by Using Spray Pyrolysis Deposition Technique
}

\author{
Jorge A. Gómez, ${ }^{1}$ Alfredo Marquez, ${ }^{2}$ Antonino Pérez, ${ }^{2}$ \\ and A. Duarte-Moller ${ }^{2}$ \\ ${ }^{1}$ Instituto Potosino de Investigación Científica y Tecnológica (IPICyT), Camino a la Presa San José 2055, \\ Colonia Lomas 4 Sección, 78216 San Luis Potosí, SLP, Mexico \\ ${ }^{2}$ Centro de Investigación en Materiales Avanzados (CIMAV), Miguel de Cervantes 120, Complejo Industrial Chihuahua, \\ 31109 Chihuahua, CHIH, Mexico
}

Correspondence should be addressed to A. Duarte-Moller, alberto.duarte@cimav.edu.mx

Received 29 June 2012; Accepted 19 November 2012

Academic Editor: Wen-Hua Sun

Copyright ( 92012 Jorge A. Gómez et al. This is an open access article distributed under the Creative Commons Attribution License, which permits unrestricted use, distribution, and reproduction in any medium, provided the original work is properly cited.

Recently alcohols and ketones have been employed to sensitize CNT by CVD. A study has shown the importance of the chemical nature of those carbon precursors on the characteristics of the CNT (carbon nanotubes) obtained. In the present work we show the influence of the catalyst employed on the synthesis of functionalized multiwall carbon nanotubes (MWCNTs) utilizing acetone as carbon source and cobalt nitrate $\mathrm{Co}\left(\mathrm{NO}_{3}\right)_{2}$ as catalyst.

\section{Introduction}

For the synthesis of carbon nanotubes are seeking a simple and economical method. It has been reported in the literature the use of carbon sources for the synthesis of carbon nanotubes as acetylene [1-4], toluene [5], nhexane, benzene and cyclopentadiene [6], and so forth, and ultimately alcohols have been used [7-13]. Montoro et al. [13] reported in a large comparative study that acetone is the best candidate to synthesize multiwall carbon nanotubes, based on this type of analysis.

Respect to the catalysts used for the synthesis of the NTC (carbon nanotubes) are used some ceramics such as alumina, impregnated in some salts such as nitrates of cobaltnickel, cobalt and manganese acetates, and various transition pure metals such as iron, cobalt, zinc, ruthenium/palladium, and Co Na-Y. Inoue and Kikuchi [9] explained that cobalt, compared with iron, exhibits a poor interaction with the coal, but better to decompose ethanol. This also shows a preference between catalysts for the nucleation and growth according to Huh et al. $[14,15]$, as well as the size of the particle. Furthermore Liu et al. [16] prepared composites based on polyamide and functionalized carbon nanotubes.

In the present study, acetone was selected as a carbon source and nitrate of cobalt as a catalyst, which will assess their performance in the synthesis of carbon nanotubes along the tube to spray synthesis, and it will also consider the ketone and nitrate groups from the breakdown of these compounds on the functionalization of multiwall carbon nanotubes.

\section{Experimental Details}

A solution was prepared at $0.42 \mathrm{M}$ with acetone at $99.6 \%$ purity supplied by JT Baker and cobalt nitrate hexahydrate $\left(\mathrm{Co}\left(\mathrm{NO}_{3}\right)_{2} \cdot 6 \mathrm{H}_{2} \mathrm{O}\right)$ at $99.0 \%$ purity supplied by Acros Organic that has been used as catalyst. A argon flow at 99.999\% purity was used as carrier gas.

Figure 1 [5] shows the pyrolytic system employee for the synthesis of the carbon nanotubes multilayer (MWCNT) 


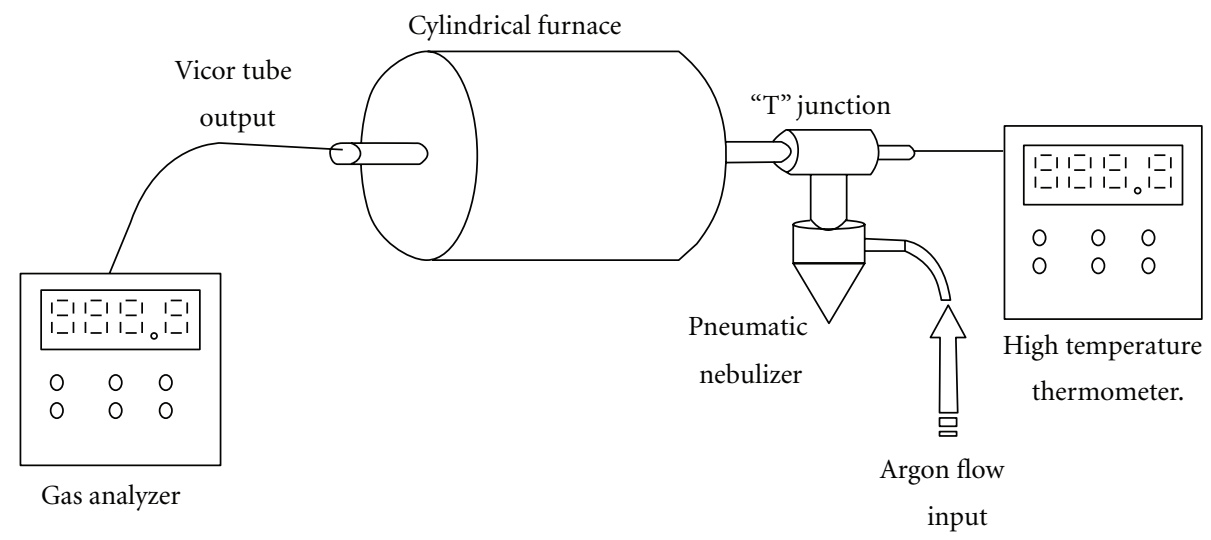

FIGURE 1: Spray pyrolysis system with a gas measurements equipment employed.

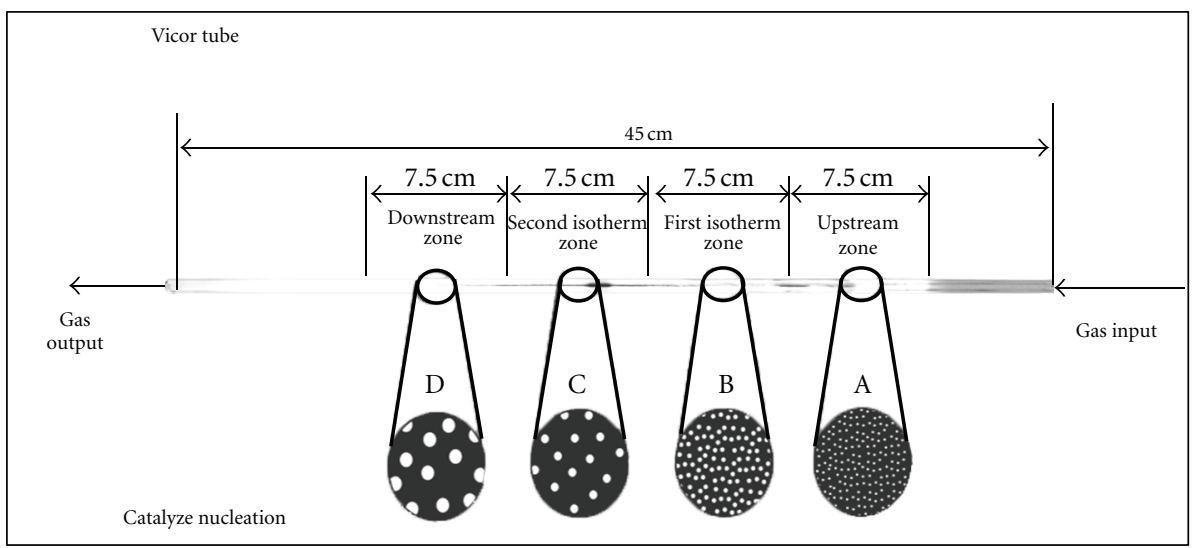

FIgURE 2: Vicor tube image, with measurements and identification of zones.

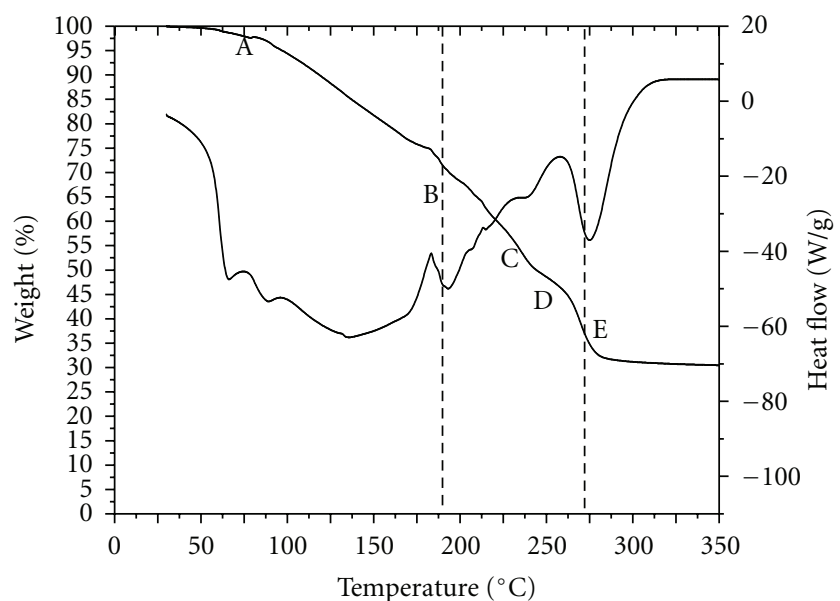

FIGURE 3: Cobalt nitrate decomposition DSC analysis.

of acetone-cobalt; in turn it shown the connection way of equipment used to measure inlet temperature, as well as the composition of the flue gases. For this synthesis was used Thermolyne cylindrical furnace $40 \mathrm{~cm}$ in length. A vicor tube of $45 \mathrm{~cm}$ in length and $9 \mathrm{~mm}$ internal diameter was used as

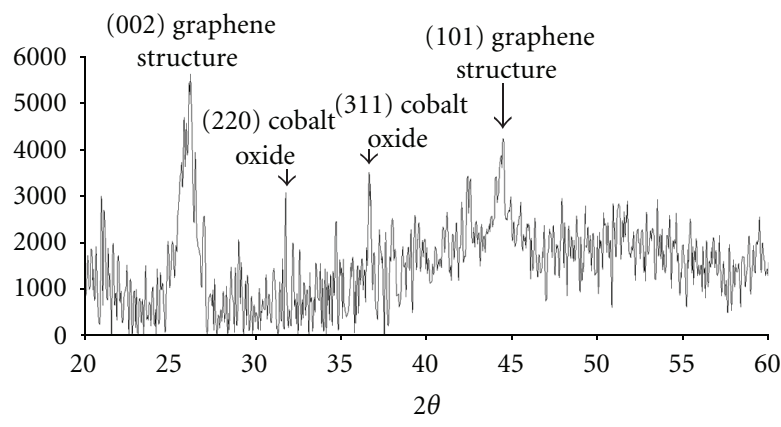

FIgURE 4: RX diffraction of carbon nanotubes.

the substrate placed inside the oven. Figure 2 shows the division of the zones of the tube considered in the analysis after the reaction has been carried out; the upstream zone is the part at the entry of the tube; in this zone it is where the acetone and the catalyst, which they have previously been nebulized, enter to vicor tube and this is where the decomposition reaction begins that continues along the tube. First isotherm zone, second isotherm zone are the two middle parts of the tube and the downstream zone is the part of the exhaust gas resulting from the decomposition and synthesis of NTC. 


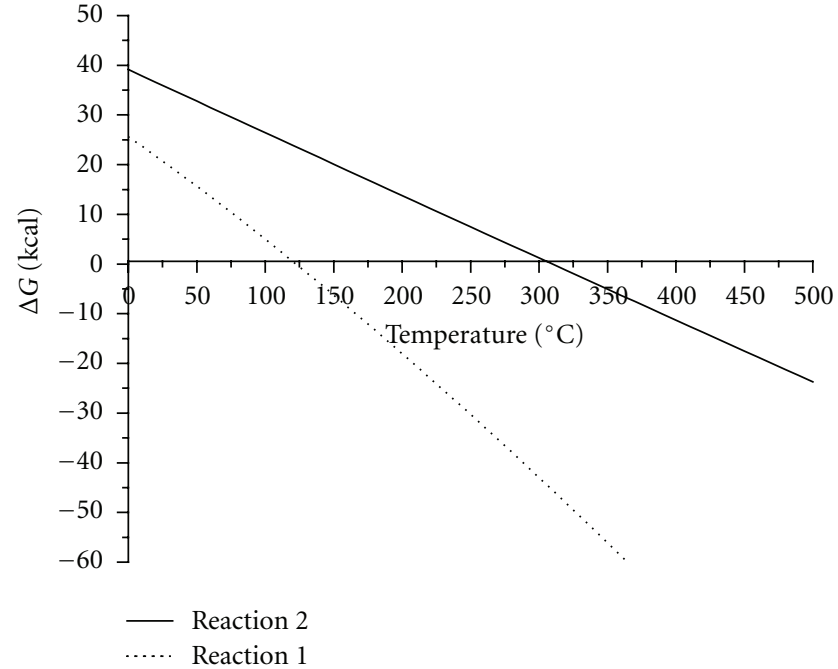

FIGURE 5: Energy formation $\Delta G$ analysis of cobalt nitrate deshidratation and decomposition.

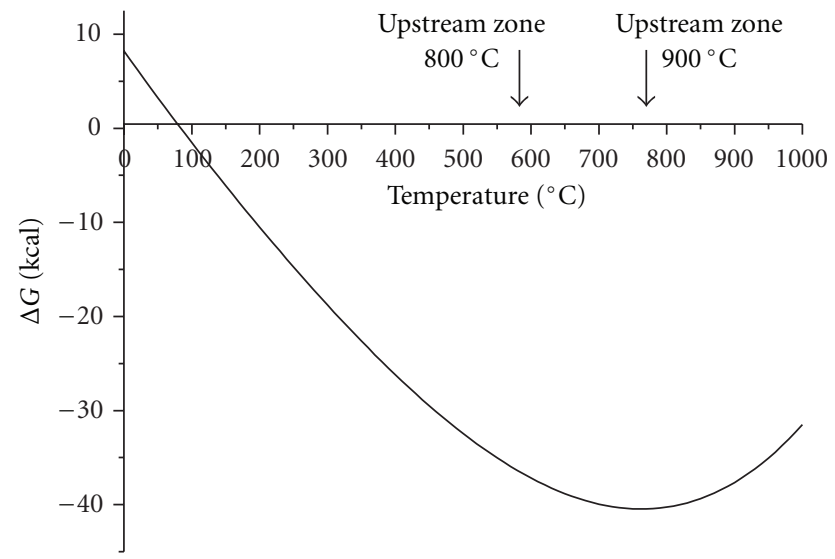

Figure 6: Energy formation $\Delta \mathrm{G}$ analysis of acetone decomposition.

TABle 1: Decomposition of cobalt nitrate (from 25 to $400^{\circ} \mathrm{C}$ ).

\begin{tabular}{lcc}
\hline Formula & $\begin{array}{c}\text { Weight loss }(\%) \\
\text { Percent weight }\end{array}$ & Accumulative \% \\
\hline $\mathrm{Co}\left(\mathrm{NO}_{3}\right)_{2} * 6 \mathrm{H}_{2} \mathrm{O}$ & 100 & - \\
$\mathrm{H}_{2} \mathrm{O}$ & 37.140 & 62.86 \\
$\mathrm{NO}_{2}$ & 15.808 & 47.052 \\
$\mathrm{O}_{2}$ & 10.995 & - \\
$\mathrm{NO}$ & 10.310 & 25.747 \\
$\mathrm{CoO}$ & 25.747 & \\
\hline
\end{tabular}

We used a set of gas analyzers CGT-7000 (infrared gas analyzer) and the NOA-7000 $\left(\mathrm{NO}_{x}, \mathrm{O}_{2}\right.$ gas analyzer) in order to monitor the exit of the product gases of the reaction to the exit of the vicor tube during the synthesis. In addition a thermocouple was attached in the area to monitor the upstream zone initial temperature at the entrance of the tube and this is where our experience shows the best carbon nanotubes synthesized in this technique (Figure 1).
TABLE 2: Cobalt nitrate-acetone decomposition. Weight loss.

\begin{tabular}{lccc}
\hline \multicolumn{4}{c}{ Cobalt nitrate decomposition during reaction } \\
Oven temp. & Spraying temperature & $\mathrm{NO}_{x} \mathrm{ppm}$ & $\mathrm{NO}$ ppm \\
\hline $800^{\circ} \mathrm{C}$ & $30^{\circ} \mathrm{C}$ & 151.7 & 173.3 \\
$900^{\circ} \mathrm{C}$ & $30^{\circ} \mathrm{C}$ & 116.4 & 123.8 \\
\hline
\end{tabular}

For the synthesis of nanotubes were selected four temperatures $700^{\circ} \mathrm{C}, 800^{\circ} \mathrm{C}, 900^{\circ} \mathrm{C}$, and $1000^{\circ} \mathrm{C}$ and kept constant during the synthesis phase. During the preheating phase, we applied a small argon flow of $0.8 \mathrm{~L}-\mathrm{min}^{-1}$. Once the furnace temperature had been reached, the solution was applied through a spray mist whose speed is $1 \mathrm{~mL} / \mathrm{min}$ of acetone under an argon flow of $2.5 \mathrm{~L}-\mathrm{min}^{-1}$. Was nebulized a total $20 \mathrm{~mL}$ of acetone catalyst solution into the vicor tube with a flow of $3.5 \mathrm{~L}-\mathrm{min}^{-1}$. Once the solution was finished, the heating system was turn off. The assembly was allowed to cool to room temperature keeping during this process a flow of argon $0.8 \mathrm{~L} / \mathrm{min}$. The vicor tube was cut into four sections to be named, these sections to the analysis phase have been called according to the vicor tube was cut into four sections each one of $7.5 \mathrm{~cm}$ in length and was named in according to its position like upstream zone, first and second downstreamzone Isothermal zones.

In order to observe the growth of carbon nanotubes a small segment of each of these parts has been extracted and analyzed using a scanning microscope JEOL JSM7401F. Subsequently each of these segments was separately immersed in an acidic solution $(1: 3)$ nitric/sulfuric [17] and extracted carbon nanotubes from the substrate by vicor ultrasonic treatment. To remove acid residues were washed with distilled water and tri-several rinses in acetone. Finally in the cleanup phase, the specimens of each sections were suspended in acetone in order to be characterized.

A small drop of this solution was placed on a formvar copper TEM grid in order to observed the carbon nanotubes in a transmission microscope FS2200-STEM. The analysis of the presence of nanotubes and waste took place in the PANalytical X-ray spectrometer, model X'Pert PRO MPD $\mathrm{X}^{\prime}$ Celerator detector. For the analysis of the functionalization of carbon nanotubes we got the liquid solution in a range close to $70^{\circ} \mathrm{C}$ by a day and half to evaporate the solvent for suspension. After several washings with methanol was placed a small drop of the suspension in a Thermoscientific Nicolet FT IR 6700, to observe the IR spectrum. These analyses were performed only on the upstream zone area synthesized at $900^{\circ}$ given that the amount of sample collected from all others was not enough for further analysis.

\section{Results and Discussions}

3.1. Decomposition of Cobalt Nitrate Hexahydrate. In Figure 3 are identified cobalt oxide residues at the end of the test TGA/DSC, and the percentages of weight loss in water, nitrogen oxides, to be corroborated from the calculations in HSC 5.1 [18] of the percentages, are shown in Table 1. We observe a phase denitrification about $25 \%$ near $180^{\circ} \mathrm{C}$; after this phase, the system no longer holds water in its structure 


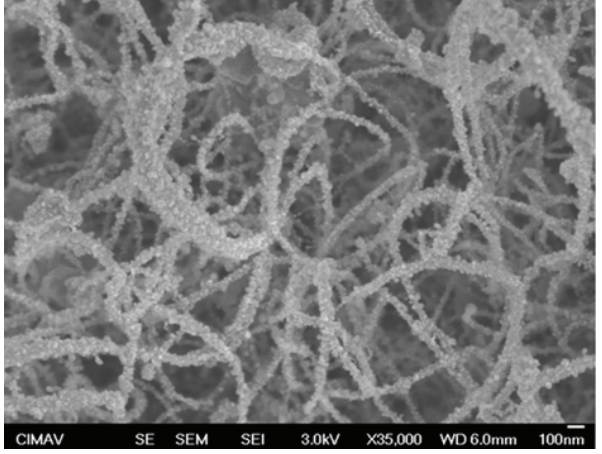

(a)

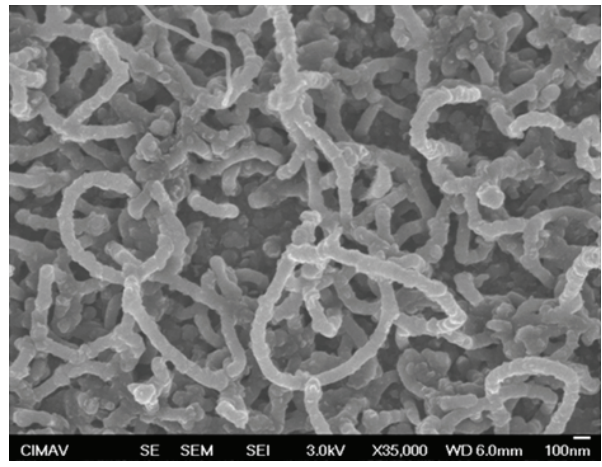

(c)

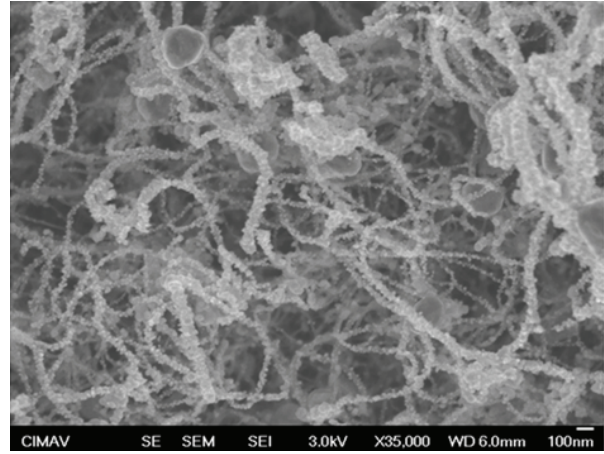

(b)

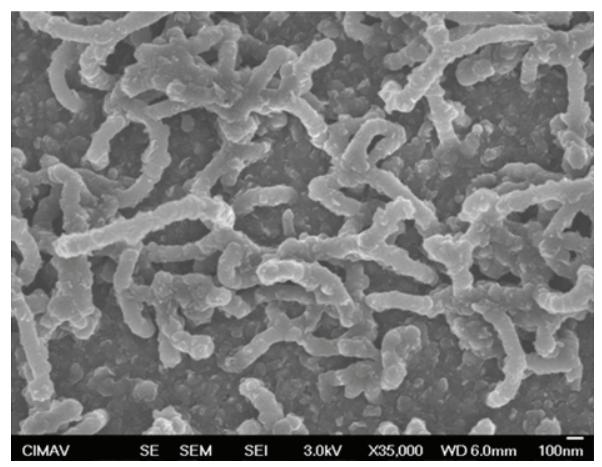

(d)

FIGURE 7: SEM images carbon nanotubes synthesized to $800^{\circ} \mathrm{C}$ of the four zones analyzed.

TABLE 3: Experimental percentage weight of propanone decomposition.

\begin{tabular}{lcccc}
\hline & & & \\
Oven temp. & Spraying temperature & Acetone decomposition & Upstream zone temperature & $\mathrm{CO} \mathrm{ppm}_{2}$ \\
\hline $800^{\circ} \mathrm{C}$ & $30^{\circ} \mathrm{C}$ & $560^{\circ} \mathrm{C}$ & 1881 & 0.02 \\
$900^{\circ} \mathrm{C}$ & $30^{\circ} \mathrm{C}$ & $774^{\circ} \mathrm{C}$ & 5754 & 0.05 \\
\hline
\end{tabular}

and then begins de-nitrification stage; this leads to the loss in weight almost $35 \%$ between $182^{\circ} \mathrm{C}$ to $275^{\circ} \mathrm{C}$; however, we see finally that a final residue of $30.37 \%$ corresponding to cobalt oxide was detected by XRD analysis, Figure 4 . We verified through a thermodynamic model for HSC, which shows the simulated results for the $\Delta \mathrm{G}$ training. The first reaction predicts the dehydration process:

$$
\mathrm{Co}\left(\mathrm{NO}_{3}\right)_{2} 6 \mathrm{H}_{2} \mathrm{O} \longrightarrow \mathrm{Co}\left(\mathrm{NO}_{3}\right)_{2}+6 \mathrm{H}_{2} \mathrm{O}
$$

The second (Reaction 2) predicts the loss of cobalt nitrate:

$$
\mathrm{Co}\left(\mathrm{NO}_{3}\right)_{2} \longrightarrow \mathrm{CoO}+\mathrm{NO}+\mathrm{NO}_{2}+\mathrm{O}_{2}
$$

We can say that the production of $\mathrm{NO}$ and $\mathrm{NO}_{2}$ occurs, given that it was possible to detect its presence (Table 2), these results were measured experimentally during the synthesis of NTC. Note also that Reaction 2 carried out effectively begins after the $300^{\circ} \mathrm{C}$ as predicted in Figure 5 .

3.2. Generation of $\mathrm{CO}, \mathrm{CO}_{2}$, and $\mathrm{H}_{2} \mathrm{O}$ to Form Carbon Nanotubes. Similarly, Figure 6 illustrates the results of the simulation graphs showing the formation $\Delta \mathrm{G}$ predicting the possible decomposition of the acetone. The reaction proposal was made based on experimental data contained in Table 3 taken to the exit of the vicor tube during a small complementary experiment about the decomposition of pure acetone. This table shows the presence of carbon monoxide and whose concentration increases with temperature:

$$
\mathrm{C}_{3} \mathrm{H}_{6} \mathrm{O} \longrightarrow \mathrm{CO}+2 \mathrm{C}+3 \mathrm{H}_{2} \uparrow
$$

Inside the vicor tube have a temperature gradient caused by the thermocouple was placed in to middle of the tubular furnance. Now we can say that the decomposition reaction of acetone starts to occur around $100^{\circ} \mathrm{C}$ almost at the entrance of the tube. Complementarily note in Figure 3 that while the acetone is beginning to decompose to $\mathrm{CO}$ and hydrogen, cobalt nitrate is just beginning to lose water. This water vapor and $\mathrm{CO}$ and $\mathrm{CO}_{2}$ and this is formed as Nasibulin et al. extra hydrogen [19]. This water vapor, $\mathrm{CO}$ and $\mathrm{CO}_{2}$ formed an extra hydrogen amount Nasibulin et al. [19]. That the unreacted CO (Table 3) reduced cobalt oxides [20] and begins to generate a unstable cobalt carbides. This is 

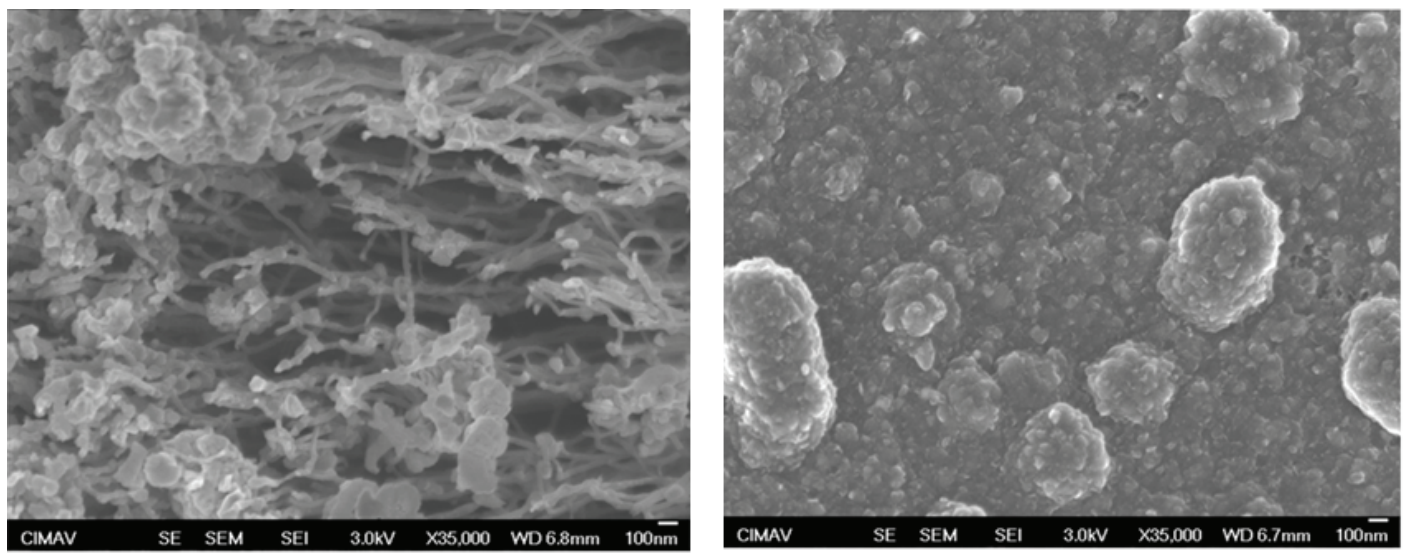

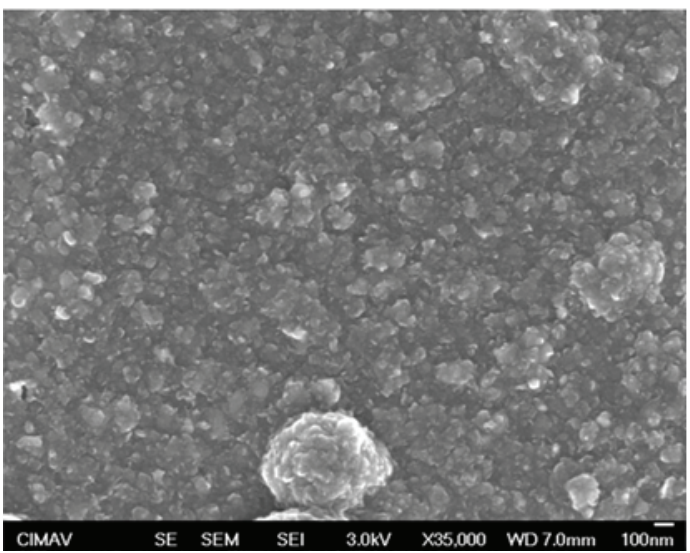

(a)

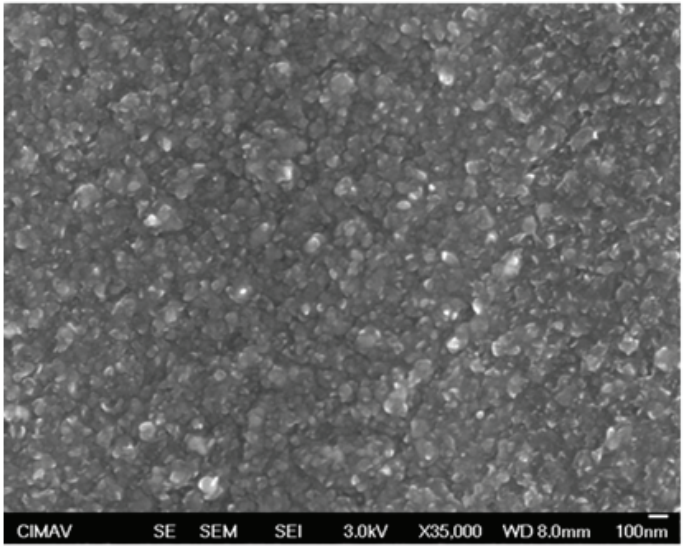

(b)

FIGURE 8: SEM images carbon nanotubes synthesized to $900^{\circ} \mathrm{C}$ of the four zones analyzed.

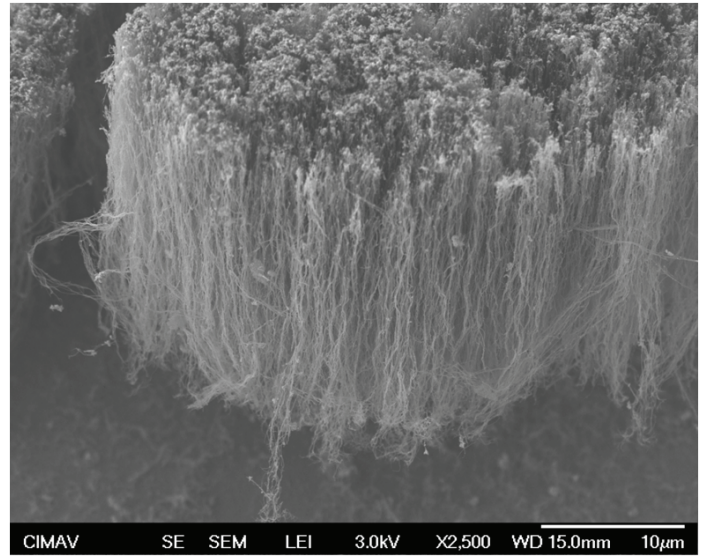

FIGURE 9: Well-aligned forest of carbon nanotubes synthesized to $900^{\circ} \mathrm{C}$ for the upstream zone.

the initial steps for the synthesis of carbon nanotubes by disproportionalization CO $[19,20]$ which is the source of carbon for the synthesis of carbon nanotubes. Nasibulin explained that the $\mathrm{CO}_{2}$ and water "clean" the precipitated amorphous carbon on the surface of the nanotubes, as well as preventing the inhibition of the catalytic particle and

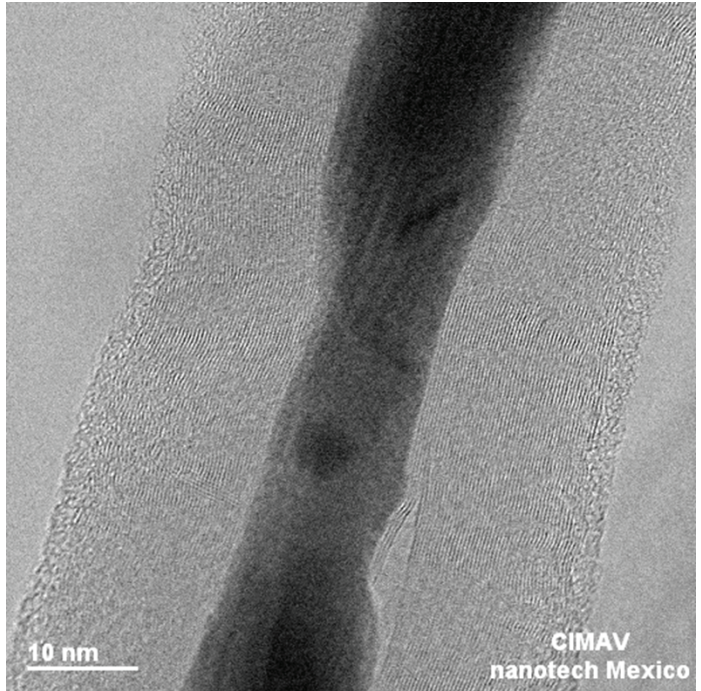

FIGURE 10: TEM images of carbon nanotubes of first isothermal zone synthesized to $900^{\circ} \mathrm{C}$.

maintaining the conditions of the formation of nanotubes by disproportionalization and hydrogenation.

As mentioned, the decomposition reaction begins to occur once the nebulized solution enters the tube synthesis. 


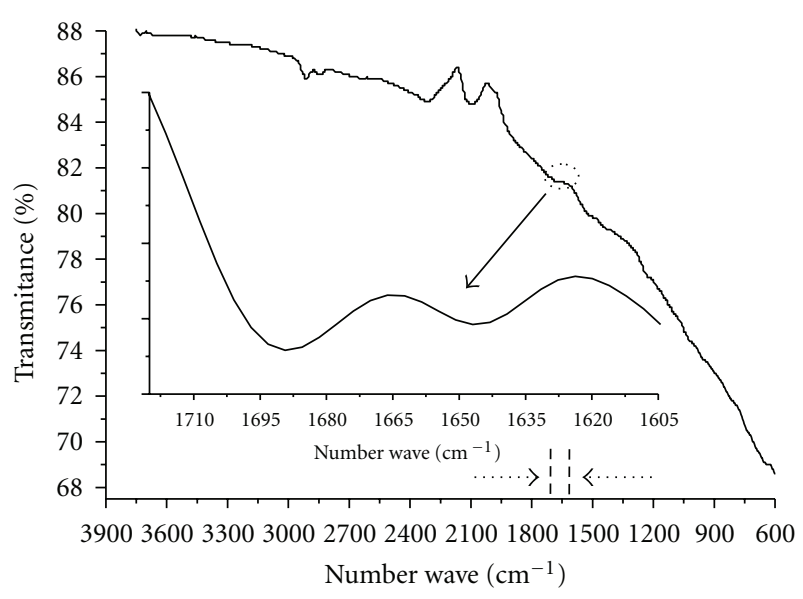

FIGURE 11: FT IR image of carbon nanotubes of first isothermal zone.

The catalyst particles begin to grow from the inlet to the outlet vicor tube (Figure 2), with a particle size of smaller cobalt at the entrance of the tube and as it moves over the tube, these particle sizes are increasingly large; this is due to that particles have the enough nucleation time. In accordance with what stated by Shin et al. [15], the systematic morphology of the catalyst, such as the grain size and density of the transition metals, controls the diameter and length of the nanotubes, which explains the differences in size and morphology of the nanotubes synthesized at $800^{\circ} \mathrm{C}$.

Figure 8 shows SEM images of the four zones synthesized at $800^{\circ} \mathrm{C}$, according to Figure 2. Also shown the nanotube formation in the four areas of vicor tube. Figure 7(a) in the image area corresponding to the upstream zone were observed thinner and longer nanotubes with small protrusions attached to hemispherical surface. These bumps are most likely composed of amorphous carbon. In the Figure 7(a) show a first isothermal zone image were observed nanotubes smaller and a bit thicker than in the previous area but fewer. In Figure 7(c) show the second isothermal zone, it is observed that the nanotubes are slightly shorter than in the first isothermal zone, but thicker than in the upstream zone. Finally, in the downstream zone, see Figure $7(\mathrm{~d})$, carbon nanotubes are thicker than the last three areas, but in smaller numbers. Some of these nanotubes appear to be linked to form a "Y".

Figure 8 illustrates the synthesis of NTC at $900^{\circ} \mathrm{C}$; we observed the formation of carbon nanotubes only in the upstream zone, while in the other three areas (first isotherm zone, second isotherm zone, and downstream zone) of the tube vicor, there were no structures similar to a nanotube. Indeed, we observe in Figure 8(a), an orderly and uniform growth of these nanotubes has occurred only in the upstream zone at $900^{\circ} \mathrm{C}$. For the first isotherm zone in Figure 8(b), were observed certain amorphous carbon conglomerations almost $300 \mathrm{~nm}$ in diameter and about one micron in length. For the second isotherm zone $8 \mathrm{C}$, were found scarce conglomerations spherical of near $200 \mathrm{~nm}$ radio of amorphous carbon. For upstream zone, 8D, there was no structure whatsoever. Figure 9 illustrates the forest of carbon nanotubes obtained in the upstream zone at $900^{\circ} \mathrm{C}$, where appreciate the orderly growth. It is important comment, these nanotubes were longer, thiner and more numerous than those synthesized to $800^{\circ} \mathrm{C}$. Nasibulin et al. [19] showed that the reactions that keep the formation of carbon nanotubes (disproportionalization and hydrogenation) are extinguished at temperatures above the $908^{\circ} \mathrm{C}$ due to the dominant role of these reversible reactions. Due to this fact, we observe that the formation of nanotubes along the tube at $800^{\circ} \mathrm{C}$ was found in all four segments of vicor tube, whereas in the $900^{\circ} \mathrm{C} \mathrm{a}$ satisfactory growth occurred only in the first zone (Figures 9 and 10), given that there were no carbon nanotubes at $1000^{\circ}$.

Figure 10 shows a TEM image of multiwall carbon nanotubes synthesized, which shows the internal structure containing a small portion of the catalyst; it is presumably of cobalt or carbide. One can also observe a thin outer layer of amorphous carbon which covers it. On Figure 11, in reference of the FT IR spectrum, show the possible evidence of functional groups $\left(-\mathrm{NO}_{2}\right)$ near the wave numbers 1640 and 1620 , and also the ketone groups close to the wave numbers 1725 and 1705. Hanming Lui [16] synthesized functionalized nanotubes where the results are similar in the morphology of carbon nanotubes.

\section{Conclusions}

The synthesis of carbon nanotubes with cobalt nitrate and acetone using the method of spray pyrolisis resulted, in addition to the carbon source and metallic cobalt as a catalyst, water and $\mathrm{CO}_{2}$ to remain in the good condition formation of carbon nanotubes. An incomplete decomposition reaction of these two compounds resulted in several functional groups adhered to the graphemic structure of the nanotubes. In which, that was possible to detect a little amount in FT IR equipment.

The water produced by the same cobalt nitrate participates in the formation of $\mathrm{CO}_{2}$ from $\mathrm{CO}$ decomposition product of acetone is proposed where additional work is controlled hydration of cobalt nitrate to observe the effect of growth and quality of carbon nanotubes. In addition to change the way of collection of catalyst particles to increase the production of multiwall carbon nanotubes, we most control the use of the reagents.

\section{References}

[1] S. Seelan, D. W. Hwang, L. P. Hwang, and A. K. Sinha, "Synthesis of multiwalled carbon nanotubes by high-temperature vacuum annealing of amorphous carbon," Vacuum, vol. 75, no. 2, pp. 105-109, 2004.

[2] Z. X. Xu, J. D. Lin, V. A. L. Roy, Y. Ou, and D. W. Liao, "Catalytic synthesis of carbon nanotubes and carbon spheres using Kaolin supported catalyst," Materials Science and Engineering B, vol. 123, no. 2, pp. 102-106, 2005.

[3] E. Terrado, M. Redrado, E. Muñoz, W. K. Maser, A. M. Benito, and M. T. Martínez, "Carbon nanotube growth on cobaltsprayed substrates by thermal CVD," Materials Science and Engineering C, vol. 26, no. 5-7, pp. 1185-1188, 2006.

[4] S. Lim, A. Shimizu, S. H. Yoon, Y. Korai, and I. Mochida, "High yield preparation of tubular carbon nanofibers over 
supported Co-Mo catalysts," Carbon, vol. 42, pp. 1279-1283, 2004.

[5] G. Alonso-Nuñez, A. M. Valenzuela-Muñiz, F. ParaguayDelgado, A. Aguilar, and Y. Verde, "New organometallic precursor catalysts applied to MWCNT synthesis by spraypirolysis," Optical Materials, vol. 29, no. 1, pp. 134-139, 2006.

[6] K. Otsuka, Y. Abe, N. Kanai, Y. Kobayashi, S. Takenaka, and E. Tanabe, "Synthesis of carbon nanotubes on Ni/carbon-fiber catalysts under mild conditions," Carbon, vol. 42, no. 4, pp. 727-736, 2004.

[7] A. Grüneis, M. H. Rümmeli, C. Kramberger et al., "High quality double wall carbon nanotubes with a defined diameter distribution by chemical vapor deposition from alcohol," Carbon, vol. 44, no. 15, pp. 3177-3182, 2006.

[8] S. Inoue, T. Nakajima, and Y. Kikuchi, "Synthesis of single-wall carbon nanotubes from alcohol using $\mathrm{Fe} / \mathrm{Co}, \mathrm{Mo} / \mathrm{Co}, \mathrm{Rh} / \mathrm{Pd}$ catalysts," Chemical Physics Letters, vol. 406, no. 1-3, pp. 184187, 2005.

[9] S. Inoue and Y. Kikuchi, "Diameter control and growth mechanism of single-walled carbon nanotubes," Chemical Physics Letters, vol. 410, no. 4-6, pp. 209-212, 2005.

[10] L. Zheng, X. Liao, and Y. T. Zhu, "Parametric study of carbon nanotube growth via cobalt-catalyzed ethanol decomposition," Materials Letters, vol. 60, no. 16, pp. 1968-1972, 2006.

[11] D. Nishide, H. Kataura, S. Suzuki, S. Okubo, and Y. Achiba, "Growth of single-wall carbon nanotubes from ethanol vapor on cobalt particles produced by pulsed laser vaporization," Chemical Physics Letters, vol. 392, no. 4-6, pp. 309-313, 2004.

[12] G. Ortega-Cervantez, G. Rueda-Morales, and J. Ortiz-López, "Catalytic CVD production of carbon nanotubes using ethanol," Microelectronics Journal, vol. 36, no. 3-6, pp. 495498, 2005.

[13] L. A. Montoro, P. Corio, and J. M. Rosolen, "A comparative study of alcohols and ketones as carbon precursor for multiwalled carbon nanotube growth," Carbon, vol. 45, no. 6, pp. 1234-1241, 2007.

[14] Y. Huh, M. L. H. Green, Y. H. Kim, J. Y. Lee, and C. J. Lee, "Control of carbon nanotube growth using cobalt nanoparticles as catalyst," Applied Surface Science, vol. 249, no. 1-4, pp. 145-150, 2005.

[15] Y. M. Shin, S. Y. Jeong, H. J. Jeong et al., "Influence of morphology of catalyst thin film on vertically aligned carbon nanotube growth," Journal of Crystal Growth, vol. 271, no. 1-2, pp. 81-89, 2004.

[16] H. Liu, X. Wang, P. Fang et al., "Functionalization of multi-walled carbon nanotubes grafted with self-generated functional groups and their polyamide 6 composites," Carbon, vol. 48, no. 3, pp. 721-729, 2010.

[17] S. Porro, S. Musso, M. Vinante et al., "Purification of carbon nanotubes grown by thermal CVD," Physica E, vol. 37, no. 1-2, pp. 58-61, 2007.

[18] HSC 5.1. Chemistry, http://www.hsc-chemistry.net/.

[19] A. G. Nasibulin, D. P. Brown, P. Queipo, D. Gonzalez, H. Jiang, and E. I. Kauppinen, "An essential role of CO2 and $\mathrm{H} 2 \mathrm{O}$ during single-walled CNT synthesis from carbon monoxide," Chemical Physics Letters, vol. 417, no. 1-3, pp. 179-184, 2006.

[20] W. Zhang, D. Ma, J. Liu, L. Kong, W. Yu, and Y. Qian, "Solvothermal synthesis of carbon nanotubes by metal oxide and ethanol at mild temperature," Carbon, vol. 42, pp. 23292366, 2004. 

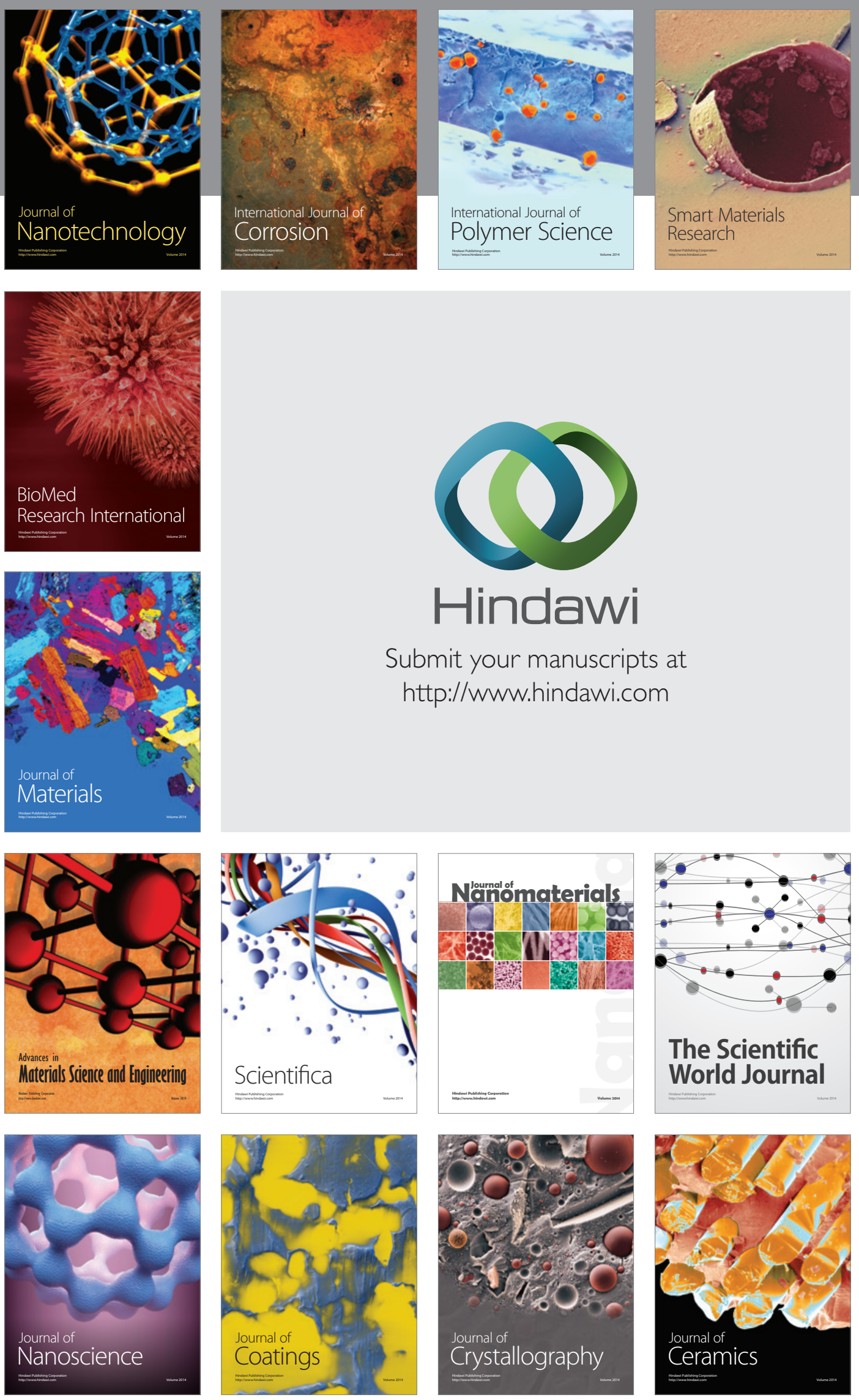

The Scientific World Journal

Submit your manuscripts at

http://www.hindawi.com

\section{World Journal}

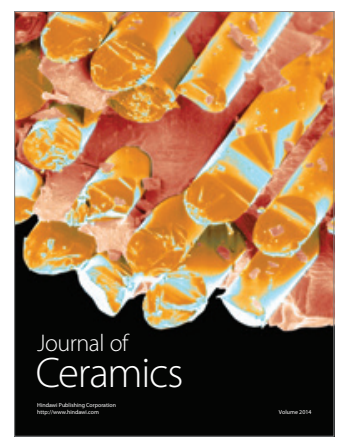

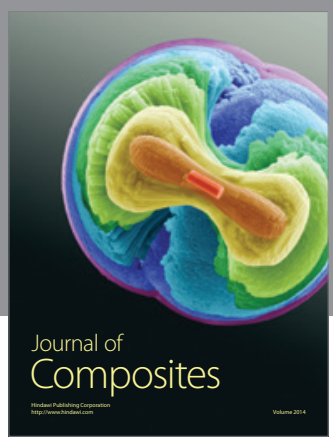
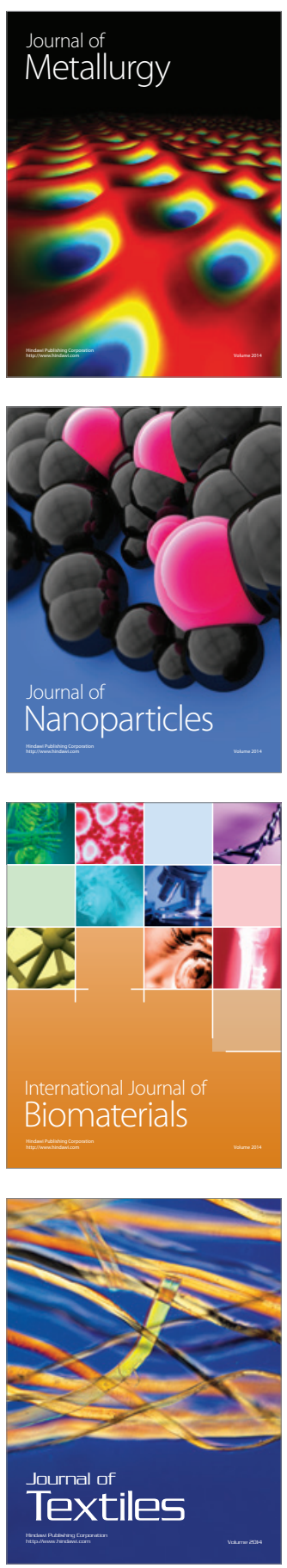